\title{
Acute Inflammatory Response in the Stomach of BALB/c Mice Challenged with Coccoidal Helicobacter pylori
}

\author{
EMA Rabelo-Gonçalves ${ }^{+}$, NF Nishimura, JMR Zeitune
}

Laboratório de Bacteriologia, Centro de Diagnóstico de Doenças do Aparelho Digestivo-Gastrocentro, Universidade Estadual de
Campinas, Rua Carlos Chagas 420, 13083-970 Campinas, SP, Brasil

An experimental murine model was used to verify the viability and pathogenicity of coccoid Helicobacter pylori. For this purpose, $27 \mathrm{BALB} / \mathrm{c}$ mice were inoculated intragastrically with $1 \mathrm{ml}$ broth culture (10 organisms $/ \mathrm{ml}$ ) of a coccoid $\mathrm{H}$. pylori clinical isolate. The animals were divided into two groups. Nine were infected on a one-time basis (GA1) and 18 were infected on two consecutive days (GA2). Other 27 mice were inoculated with Brucella broth and divided in the same way; they composed the control group. Mice were killed at 2, 3, 7, 14 and 21 days post inoculation (pi). Fragments of stomach and duodenum were collected, fixed with 12\% formalin and stained by hematoxilin-eosin and Giemsa for histopathological examination. Until the 14th day, only reinfected mice had mildto-moderate inflammatory infiltrate in the stomach. The infiltration was predominantly lymphomonocytic, although plasma cells and eosinophils could be seen. However, at 21 st day, severe eosinophilic infiltration was present in the lamina propria and submucosa of gastric corpus. In subgroup GA1, animals presented lymphomonocytic infiltration in the stomach from 14th day pi. Our results showed that coccoid $\mathrm{H}$. pylori was able to induce an acute inflammatory response in stomach of reinfected mice since the initial periods of infection.

Key words: Helicobacter pylori - morphology - animal model

Helicobacter pylori is a gram-negative spiral bacterium first isolated in 1982 from a patient with chronic active gastritis (Marshall \& Warren 1984). Infection of the human gastric mucosa by $H$. pylori is associated with gastritis, peptic ulcer disease and gastric cancer (Ghiara et al. 1995, Takahashi et al. 1998). The bacterium is now considered the most prevalent organism that occurs in humans; about $50 \%$ of the human population is estimated to be infected (Fox et al. 2000).

H. pylori, as well as Vibrio-like bacteria, shows two different morphologic aspects: spiral and coccoid form, the latter observed in vivo and induced in vitro under stress conditions (Cellini et al. 1994a, 1998, Kusters et al. 1997, Lee et al. 1997, Donelli et al. 1998). These conditions include aerobiosis, alkaline $\mathrm{pH}$, high temperature, extended incubation, treatment with a proton pump inhibitor or antibiotics and exposition to nitric-oxide generators in vitro (Cole et al. 1997, 1999, Mizoguchi et al. 1998).

During infection the majority of $H$. pylori have a bacillary appearance; however, coccoid forms can be found in human stomach and duodenum (Chan et al. 1994, Cole et al. 1997, Kusters et al. 1997). The morphological conversion from bacillary to coccoid form can represent an adaptation of the bacteria to survive in unsuitable envi-

This work was supported by Fundação de Amparo à Pesquisa do Estado de São Paulo (Grant 99/07821-0).

Corresponding author. Fax: 55-19-3289.1682. E-mail: emargoncalves@yahoo.com.br

Received 6 March 2002

Accepted 25 October 2002 ronments (Cellini et al. 1994b). Furthermore, coccoid $H$. pylori may remain in the gastric mucosa after anti- $H$. pylori treatment of patients in three forms: a degenerative dead form, a viable non-culturable form and a viable culturable form (Andersen et al. 2000).

Although several investigators have suggested that coccoid $H$. pylori represents a degenerative form with no infectious capability, others have reported that it retains a weak metabolic activity, important structural components and pathogenicity (Mizoguchi et al. 1998). It has been described that coccoid form may play a role in the transmission of bacteria and may be involved in the recrudescence or relapse of infection after antimicrobial therapies (Janas et al. 1995, Shirai et al. 2000). Some authors have related that coccoid forms can be found attached to severely damaged gastric epithelial cells and are prevalent around margins of gastric tumors (Chan et al. 1994, Cole et al. 1997). In fact, this form can be identified in $93 \%$ of biopsy specimens from patients with $H$. pylori-associated adenocarcinoma (Cole et al. 1997). Other researchers have demonstrated that coccoid $H$. pylori exhibits antigenic components absent in the bacillary forms and recognized by sera of infected patients (Benaissa et al. 1996). Additionally, successful infection with coccoid forms of H. pylori or Campylobacter jejuni in animal models has been reported (Jones \& Curry 1991, Cellini et al. 1994a, Wang et al. 1997).

In the present study, we performed a murine experimental model for $H$. pylori infection to verify the viability and pathogenicity of $H$. pylori coccoid form.

\section{MATERIALS AND METHODS}

Animals - Male BALB/c mice were obtained from Centro Multi-instituicional de Bioterismo-Cemib, Universidade Estadual de Campinas-Unicamp, Campinas, 
SP, Brazil and maintained under specific pathogen free (SPF) conditions. They were 6-8 weeks old when challenged. During experimental period, mice were fed with a sterilized commercial rodent diet and with sterilized water ad libitum. They were maintained in an ordinary environment. This study was performed with the approval of the Biological Institute/Unicamp Ethical Committee for Animal Research (authorization 80-2, 1999).

Bacterial isolation - A fresh clinical isolate of $H$. pylori, obtained from a patient with active duodenal ulcer, was used in our study. The rapid urease test was positive for this patient. The strain was isolated in Belo Horizonte Medium (BHM) (Queiroz et al. 1987), at seven days of incubation at $37^{\circ} \mathrm{C}$ under microaerophilic atmosphere (Microaerobac, Probac, São Paulo, SP) in an anaerobic jar (Difco Laboratories, Detroit, Michigan, USA). After isolating, the bacteria was identified by Gram staining and biochemical tests of urease, catalase and oxidase.

Bacterial inoculum - After isolation on agar plates, the strain was inoculated in Brucella Broth (Difco Laboratories) supplemented with $2 \%$ fetal calf serum (FCS) (Difco Laboratories) and incubated under microaerophilic atmosphere at $37^{\circ} \mathrm{C}$ without agitation for $72 \mathrm{~h}$ to obtain the coccoid morphology. The density of bacteria in the broth culture was adjusted according to methodology previously described (Shomer et al. 1998), to a concentration of approximately $10^{8}$ organisms $/ \mathrm{ml}$.

Experimental design - Twenty-seven mice were divided into two groups: in GA1, 9 animals were inoculated intragastrically, with $1 \mathrm{ml}$ of suspension, on a one-time basis, after one day of fasting, with an urethral pediatric probe no. 04 (Embramed, São Paulo, SP, Brazil). In GA2, 18 animals were inoculated in the same way, on two consecutive days.

Other 27 mice were divided into two groups: in GB1, 9 animals were inoculated intragastrically, with $1 \mathrm{ml}$ of Brucella Broth supplemented with $2 \% \mathrm{FCS}$, in a one-time basis, after one day of fasting, with an urethral pediatric probe no. 04 (Embramed, São Paulo, SP, Brazil). In GB2, 18 animals were inoculated in the same way, on two consecutive days.

Animals from each subgroup were killed by cervical dislocation at 2, 3, 7, 14 and 21 days post inoculation (pi). The stomach and duodenum were collected, washed with sterile saline and divided for histopathological study.

Histopathology - Stomach and duodenum samples were fixed in neutral $12 \%$ formalin and processed in the usual way for parafin embedding. Five micrometer-thick sections were stained by hematoxilyn-eosin (H\&E) and Giemsa staining. The histophatological changes evaluated were: the site of inflammation (corpus, antrum, pylorus, duodenum), its composition (lymphomonocytic, lymphoplasmacytic, eosinophilic), its intensity (mild, moderate, severe), level of the infiltrate in the gastric wall and possible presence of erosions or ulcerations (Cellini et al. 1994a). In the smears stained by Giemsa, the presence of H. pylori was assessed using immersion (X1000).

Statistical analysis - Data obtained in the present study were compared by Fischer's Exact test and considered significant at values of $p \leq 0.05$.

\section{RESULTS}

Macroscopic findings - No visible gastric and duodenal alterations were seen in the mice to which $H$. pylori were administered.

Microscopic findings - No gastrointestinal erosion or ulceration was seen in the inoculated animals. During the first seven days pi, only mice reinfected with $H$. pylori (subgroup GA2) showed mild-to-moderate inflammatory infiltrate in the stomach $(p=0.0277)$. In this period, lymphocytes and macrophages composed the infiltrate, although eosinophils and plasma cells were present. Inflammation was mainly restricted to the gastric corpus and cells were generally accumulated in the lamina propria and submucosa. Some animals exhibited infiltration in the corpus mucosa. After the 14th day pi, the infiltration became severe and was composed by the same population of inflammatory cells (Fig. 3). However, mice infected at this period had a substantially diminished mononuclear infiltration in the stomach, whereas their eosinophilic response was significantly higher (Fig. 2). The gastric corpus was still the region where cells were predominantly seen. In all periods analyzed, the glandular corpus was preserved without loss of chief and parietal cells. Nevertheless, until the 14th day, mild infiltrate was observed in the pylorus of two animals in this subgroup.

In the subgroup where animals were inoculated on one time-basis (GA1), lymphomonocytic infiltration with plasma cells and eosinophils could be observed from the 14th day (Fig. 4). At the 21st day the infiltration was moderate and the number of eosinophils was augmented. Furthermore, an animal showed mild infiltration in the duodenal submucosa at this period of infection.

In the control mice challenged with Brucella broth, the only histological changes were minimal numbers of inflammatory cells in the stomach and duodenum.

Additionally, in the infected animals that presented inflammatory infiltrate, the biopsies stained by Giemsa procedure exhibited bacteria mainly in the coccoid form; bacteria in typical spiralled appearance were not seen (Fig. 5). The number of organisms decreased during infection (data not shown).

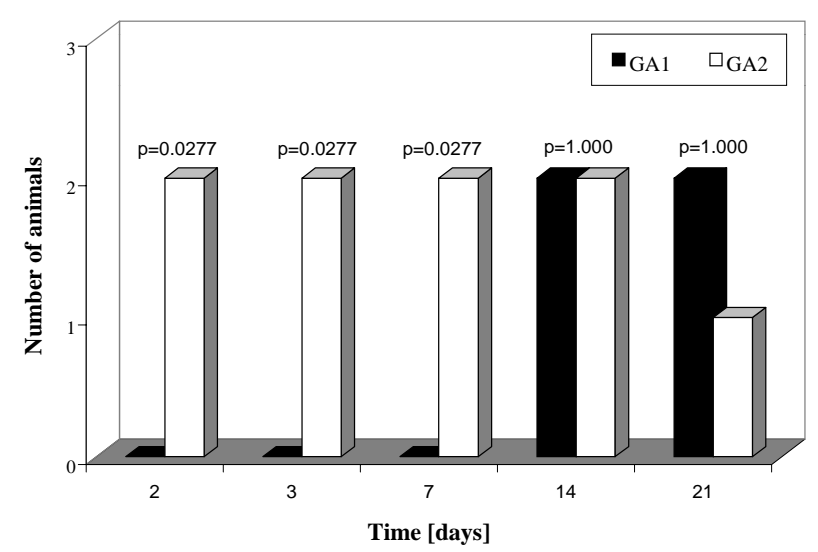

Fig. 1: number of animals with inflammatory infiltrate in the gastric corpus. GA1-animals inoculated on a one-time basis; GA2animals inoculated on a two consecutive days. 


\section{DISCUSSION}

The histopathological findings we described in this report showed that our experimental model of BALB/c mice infection, with a coccoid strain of $H$. pylori, was established since the initial periods of infection when animals were challenged on two consecutive days. The inflammatory infiltrate was observed since the 2nd day after reinoculation, although the number of animals with infiltration diminished significantly from the 14th day pi. Comparing our results with data showed by other researchers we verified that these authors had more severe histopathological alterations at delayed periods of infection (Cellini et al. 1994a, Wang et al. 1997).

In our rodent model there were no severe lesions like gastritis, duodenitis or peptic ulcer in any of inoculated mice. However, some reinoculated animals showed an intense infiltration in the gastric corpus at 21st day pi (Fig. 3). Similar results were described by Sakagami et al. (1996) who related that bacteria were almost exclusively located in the antral glands, while the inflammatory changes were restricted to the body of the stomach. In contrast, Wang et al. (1997) have found that pylorus and duodenum of BALB/c mice infected with a coccoid strain of $H$. pylori were more affected by the organism. In our study, we visualized a mild inflammatory infiltration in the duodenum of one infected animal at the 21 st day. Considering that these authors accompanied the infection during 30 weeks, we believe that a longer period of infection is necessary to obtain inflammation in the lower gastrointestinal tract of mouse.

Although Fig. 1 shows an important difference between the number of animals with infiltration in subgroups
GA1 and GA2 at the 21th day, this difference was not statistically significant $(p=1.000)$. We believe these discordant results may be a consequence of the small $n$ value we used in our experiments.

In relation to conversion of coccoid to bacillary form, we verified that bacteria were not able to conversion in our experimental study (Fig. 5). Different results were presented by Cellini et al. (1994a) who described the reversion of fresh coccoid forms in the mouse stomach. These discordant data may reflect the differential viability of coccoids, although strain diversity, contamination with spiral forms, and differential host species specificities should be considered (Mizoguchi et al. 1998).

Analyzing the population of inflammatory cells in the infiltration, we observed eosinophils presence since the initial periods of infection, but they became predominant only at the 21 th day in subgroup GA2 (Fig. 2). Cellini et al. (1994a) described similar findings in their experimental murine model of coccal $H$. pylori infection. The role of eosinophils in the human chronic gastritis induced by $H$. pylori has been studied by several authors. In the human infection, McGovern et al. (1991) reported an increase in infiltration and degranulation of eosinophils in patients with gastritis evoked by the organism. The authors suggested that during $H$. pylori infection there is an increase in secretion of IgA by plasma cells; it promotes eosinophilic influx and degranulation, favouring the antral damage. In the murine infection, Ferrero et al. (1997) have described an increased influx of plasma cells and in the secretion of $\operatorname{IgA}$ in mice infected with $H$. felis. Our results, analyzed in conjunction with studies previously done, suggest that the presence of plasma cells in the infiltra-

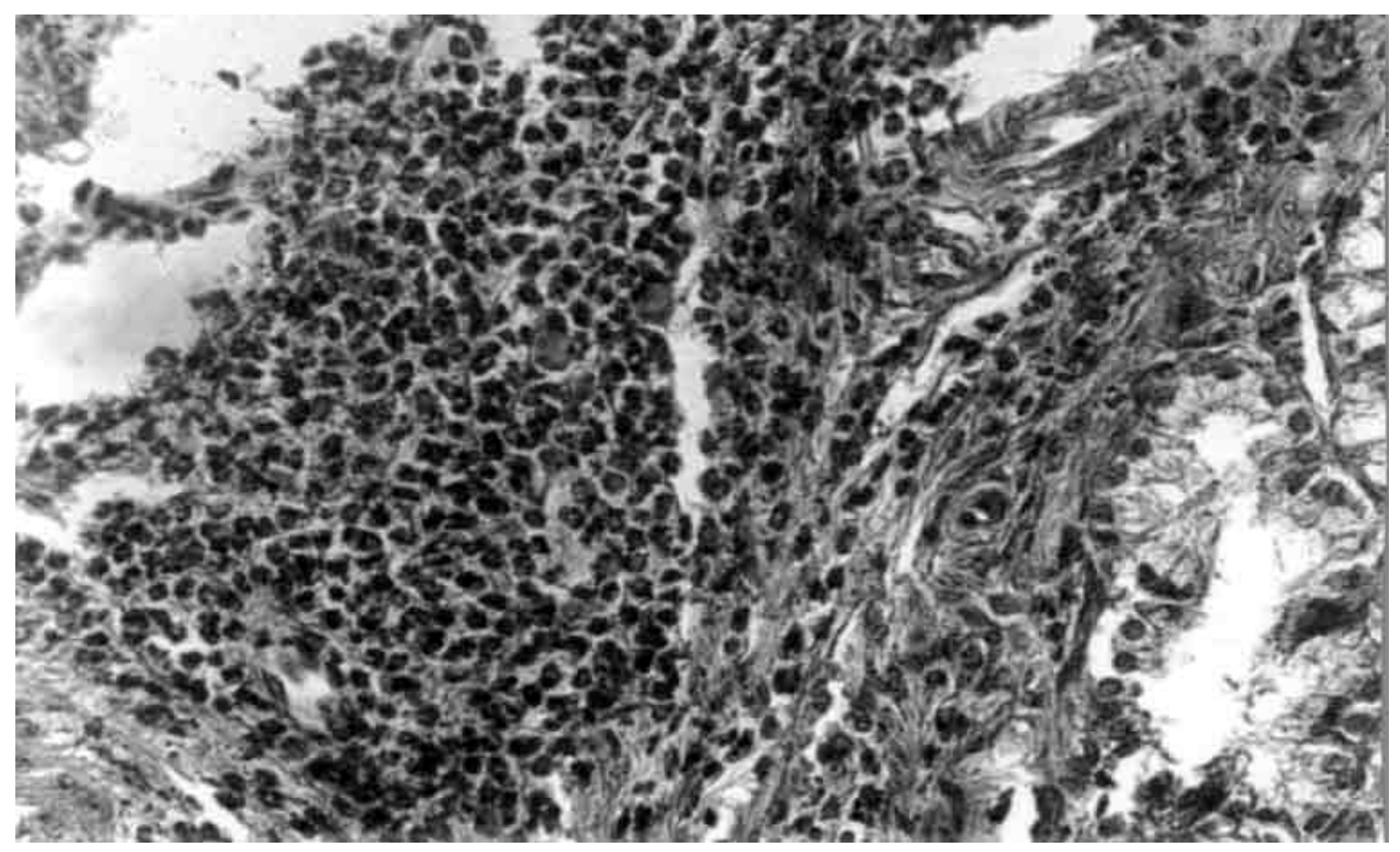

Fig. 2: eosinophilic infiltration in the submucosa of mouse gastric corpus (GA2) at the 21th day post-inoculation. H\&E. X400. 
tion induced by $H$. pylori inoculation is an important factor for ontogenesis and development of inflammatory response in the mice stomach.

We still observed the tecidual response to inoculation of coccoid $H$. pylori developed mainly in the lamina pro- pria and submucosa of challenged mice (Fig. 3). Among the inflammatory cells we frequently saw in the lamina propria, there were lymphocytes and plasma cells. These results are similar to data described by Karttunem et al. (1996) who related the prevalence of these cells in the

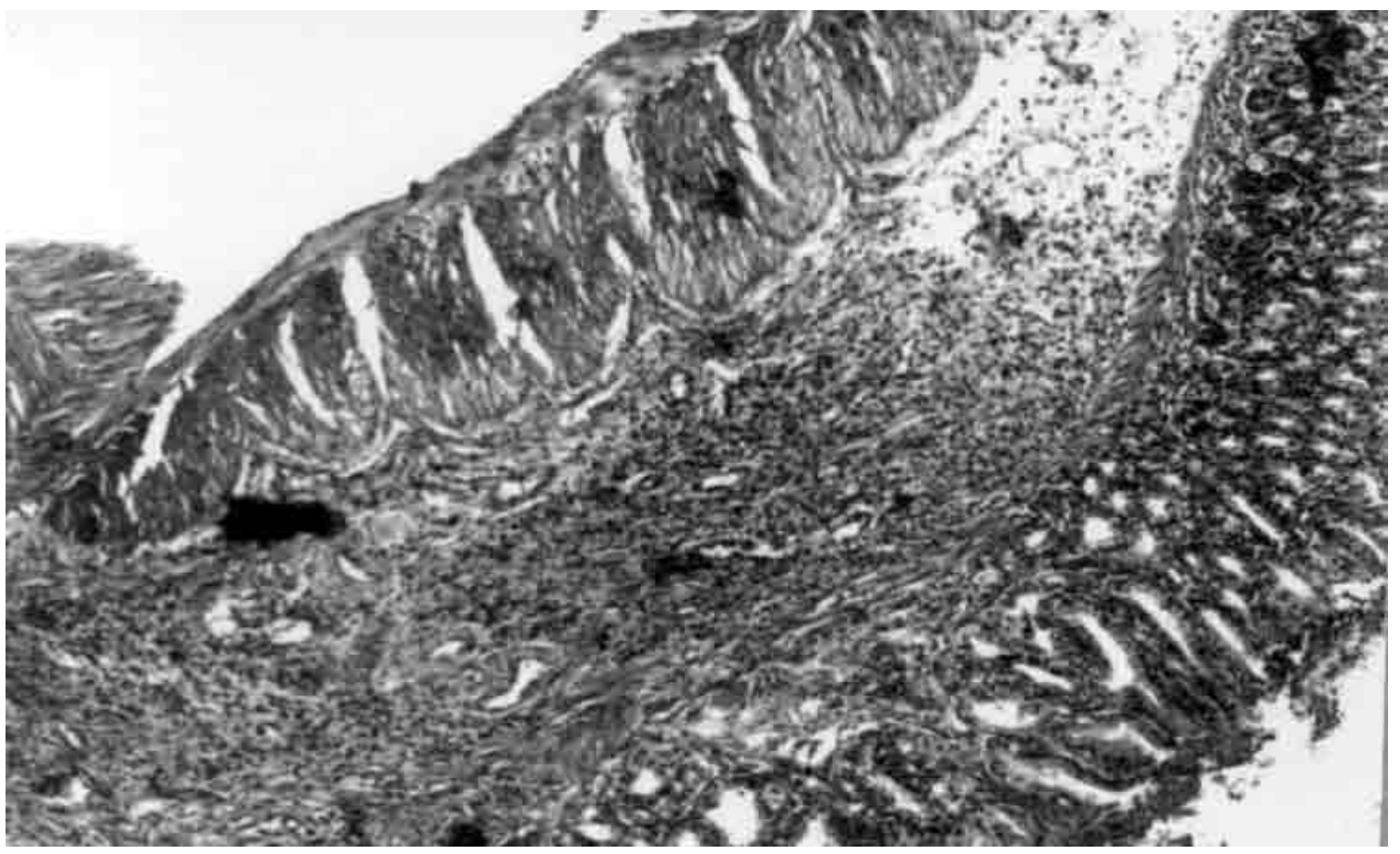

Fig. 3: general view of mouse stomach (GA2) at the 21th day post-inoculation. Severe infiltratecan be seen at lamina propria and submucosa. H\&E. X100.

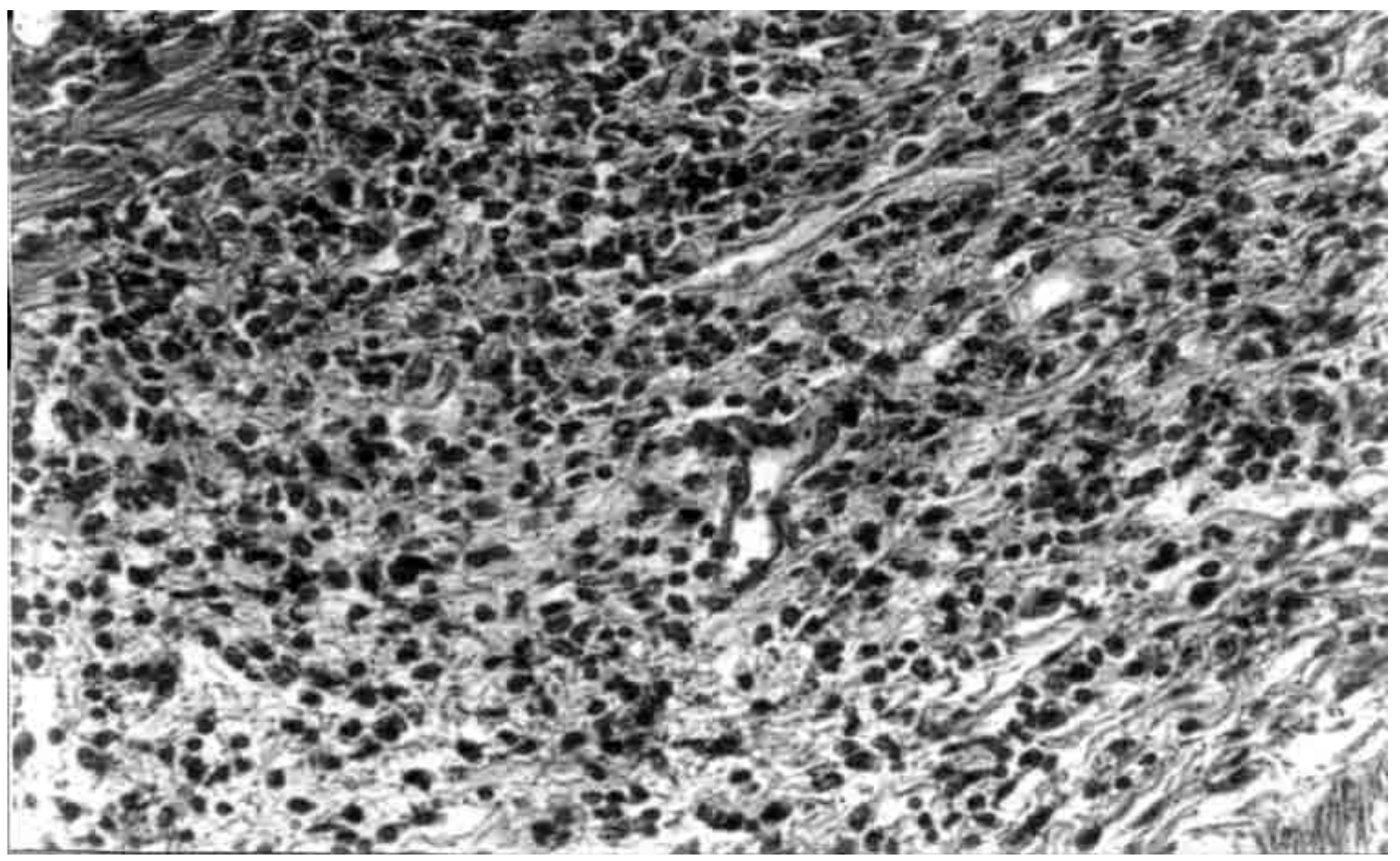

Fig. 4: lymphomonocytic infiltration in the submucosa of mouse gastric corpus (GA1) at the 14th day post-inoculation. H\&E. X400. 


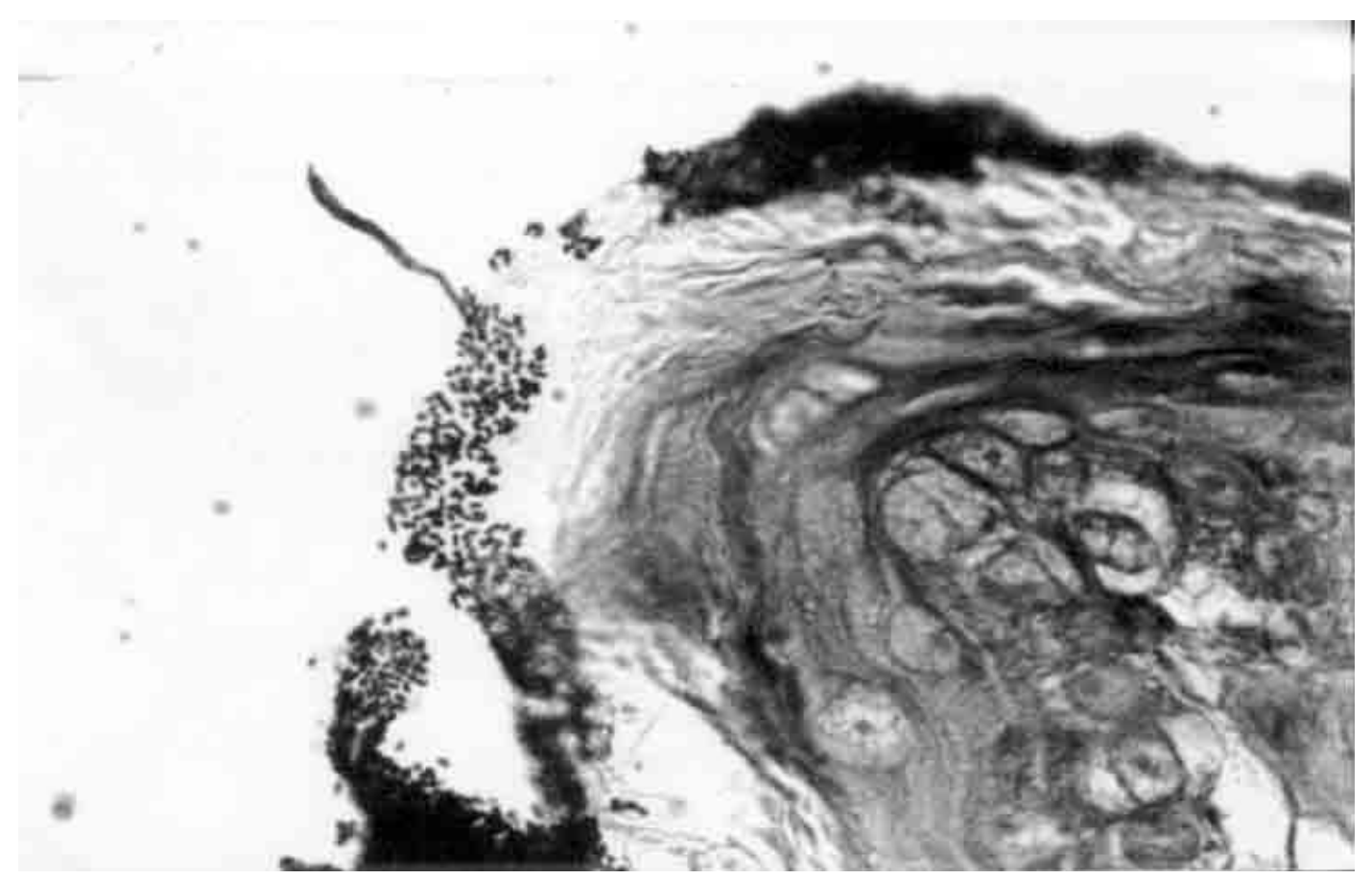

Fig. 5: coccoid forms of Helicobacter pylori in the gastric mucus of mouse stomach (GA1) at the 2nd day post-inoculation. Giemsa. X1000.

lamina propria of patients with chronic gastritis associated with $H$. pylori. Other researchers have related that a heavy immune response mounted in lamina propria of infected patients resulted from the presentation of luminal $H$. pylori antigens to immunocompetent cells underlying the gastric epithelium (Fiocca et al. 1994).

Finally, it must be considered that these histopathologic alterations may represent more a gastritis similar to the post-immunization gastritis than a response due to a true colonization. Furthermore, the finding that coccoid H. pylori was able to induce an inflammatory response in our experimental rodent model indicates that this form retains important pathogenic properties and requests further studies to elucidate its pathogenicity and relationship with gastroduodenal disease.

\section{ACKNOWLEDGEMENTS}

To José Augusto Gatto Stedile for excellent histophatological assistance. To José Geraldo P Ferraz and Marilia A Rabelo Buzalaf for valuable suggestions in preparing the manuscript.

\section{REFERENCES}

Andersen LP, Dorland A, Karacan H, Colding H, Nilsson HO, Wadstrom T, Blom J 2000. Possible clinical importance of the transformation of Helicobacter pylori into coccoid forms. Scand J Gastroenterol 35: 897-903.

Benaissa M, Babin P, Quellard N, Pezzennec L, Cenatiempo Y, Fauchére JL 1996. Changes in Helicobacter pylori ultrastructure and antigens during conversion from the bacillary to the coccoid form. Infect Immun 64: 2331-2335.

Cellini L, Allocati N, Angelucci D, Iezzi T, Di Campli E, Marzio
L, Dainelli B 1994a. Coccoid Helicobacter pylori not culturable in vitro reverts in mice. Microbiol Immunol 38: 843-850.

Cellini L, Alocatti N, Di Campli E, Dainelli B 1994b. Helicobacter pylori: a fickle germ. Microbiol Immunol 38: 25-30.

Cellini L, Robuffo I, Di Campli E, Di Bartolomeo S, Taraborelli T, Dainelli B 1998. Recovery of Helicobacter pylori ATCC 43504 from a viable but not culturable state: regrowth or resuscitation? APMIS 106: 571-579.

Chan WY, Hui PK, Leung KM, Chow J, Kwok F, Chi-Sing NG 1994. Coccoid forms of Helicobacter pylori in the human stomach. Am J Clin Pathol 102: 503-507.

Cole SP, Kharitnov VF, Guiney DG 1999. Effect of nitric oxide on Helicobacter pylori morphology. J Infect Dis 180: 17131717.

Cole SP, Cirillo D, Kagnoff MF, Guiney DG, Eckmann L 1997. Coccoid and spiral Helicobacter pylori differ in their abilities to adhere to gastric epithelial cells and induce interleukin8 secretion. Infect Immun 65: 843-846.

Donelli G, Matarrese P, Fiorentini C, Dainelli B, Taraborelli T, Di Campli E, Bartolomeo S, Cellini L 1998. The effect of oxygen on the growth and cell morphology of Helicobacter pylori. FEMS Microbiol Let 168: 9-15.

Ferrero RL, Thiberge JM, Labigne A 1997. Local immunoglobulin $\mathrm{G}$ antibodies in the stomach may contribute to immunity against Helicobacter infection in mice. Gastroenterology 113: 185-194.

Fiocca R, Luinetti O, Villani L, Chiaravalli AM, Capella C, Solcia E 1994. Epithelial cytotoxicity, immune responses and inflammatory components of Helicobacter pylori gastritis. Scand J Gastroenterol 29 (Suppl. 205): 11-21.

Fox JG, Beck P, Dangler CA, Whary MT, Wang TC, Shi HN, Nagler-Anderson C 2000. Concurrent enteric helminth in- 
fection modulates inflammation and gastric immune responses and reduces helicobacter-induced gastric atrophy. Nat Med 6: 536-542.

Ghiara P, Marchetti M, Blaser M, Tummuru MKR, Cover TL, Segal ED, Tompkins LS, Rappuoli R 1995. Role of Helicobacter pylori viruolence factors vacuolating cytotoxin, CagA and urease in a mouse model of disease. Infect Immun 63: 4154-4160.

Janas B, Czkwianianc E, Bak-Romaniszyn L, Bartel H, Tosik D, Planeta-Malecka I 1995. Electron microscopic study of association between coccoid forms of Helicobacter pylori and gastric epithelial cells. Am J Gastroenterol 90: 18291833.

Jones DM, Curry A 1991. The genesis of coccal forms of Helicobacter. In P Malfertheiner, H Ditschunet (eds), Gastritis and Peptic Ulcer, Springer, Berlin, Germany, p. 29-37.

Karttunen TJ, Niemela S, Kerola T 1996. Blood leukocyte differential in Helicobacter pylori infection. Dig Dis Sci 41: 1332-1336.

Kusters JG, Gerrits MM, Van Strijp JAG, VandenbrouckeGauls CMJE 1997. Coccoid forms of Helicobacter pylori are the morphologic manifestation of cell death. Infect Immun 65: 3672-3679.

Lee SG, Kim C, HA YC 1997. Successful cultivation of a potentially pathogenic coccoid organism with tropism for gastric mucin. Infect Immun 65: 49-54.

Marshall BJ, Warren JR 1984. Unidentified curved bacilli in the stomach of patients with gastrits and peptic ulceration. Lancet 1: 1311-1315.

McGovern TW, Talley NJ, Kephart GM, Carpenter HA, Gleich
GJ 1991. Eosinophil infiltration and degranulation in Helicobacter pylori-associated chronic gastritis. Dig Dis Sci 36: 435-440.

Mizoguchi H, Fujioka T, Kishi K, Nishizono A, Kodama R, Nasu M 1998. Diversity in protein synthesis and viability of Helicobacter pylori coccoid forms in response to various stimuli. Infect Immun 66: 5555-5560.

Queiroz DMM, Mendes EN, Rocha GA 1987. Indicator medium for isolation of Campylobacter pylori. J Clin Microbiol 25: 2378-2379.

Sakagami T, Dixon M, O'Rourke J, Hoelett R, Alderuccio F, Vella J, Shimoyama T, Lee A 1996. Atrophic gastric changes in both $H$. felis and $H$. pylori infected mice are host dependent and separate from antral gastritis. Gut 39: 639-648.

Shirai M, Kakada J, Shibata K, Morshed MG, Matsushita T, Nakazawa T 2000. Accumulation of polyphosphate granules in Helicobacter pylori cells under anaerobic conditions. J Med Microbiol 49: 513-519.

Shomer NH, Dangler CA, Whary MT, Fox JG 1998. Experimental Helicobacter pylori infection induces antral gastrits and gastric mucosa-associated lymphoid tissue in guinea pigs. Infect Immun 66: 2614-2618.

Takahashi S, Nakamura E, Okabe S 1998. Effect of cytokines, without and with Helicobacter pylori components, on mucus secretion by cultured gastric epithelial cells. Dig Dis Sci 43: 2301-2308.

Wang W, Sturegard E, Rupar R, Nilsson HO, Aleljung PA, Carlén B, Willén R, Wadstrom T 1997. Infection of BALB/c A mice by spiral and coccoid forms of Helicobacter pylori. $J$ Med Microbiol 46: 657-663. 